\title{
Educação e sociedade: o papel das Políticas de Ensino Médio na formação de estudantes em escola pública da Amazônia Paraense
}

\author{
Education and society: the role of Higher Education Policies in the training of \\ students in public school of the Amazônia Paraense

\section{Éducation et de la société: le rôle des Politiques de l'Enseignement Secondaire dans la formation des élèves à l'école publique de l'Amazônia Paraense}

\author{
Educación y sociedad: el papel de las Políticas de Enseñanza Media en la \\ formación de estudiantes en escuela pública de la Amazônia Paraense
}

\author{
Afonso Welliton de Sousa Nascimento ${ }^{1}$ \\ Yvens Ely Martins Cordeiro ${ }^{1}$ \\ Francinei Bentes Tavares ${ }^{1}$ \\ Norma Ely Santos Beltrao ${ }^{2}$
}

Recebido em 28/07/2017; revisado e aprovado em 24/09/2017; aceito em 04/10/2017

DOI: http://dx.doi.org/10.20435/inter.v19i2.1668

\begin{abstract}
Resumo: A pesquisa objetivou o estudo das políticas educativas do Ensino Médio no Estado do Pará e seu papel na formação de estudantes em uma escola pública da Amazônia Paraense, no Município de Abaetetuba, no período de 2007 a 2012. O universo da pesquisa é de uma escola que recebe alunos dos bairros periféricos da cidade e provenientes do campo: estradas e ilhas. Foi constatado o reflexo negativo da política educacional na formação traduzida pela fragilidade dos conteúdos ministrados, em especial para a continuidade dos estudos.
\end{abstract}

Palavras-chave: política educacional; formação; estudante; Amazônia.

Abstract: The research aimed at the study of the educational policies of High School in the State of Pará and its role in the training of students in a public school in the Amazônia Paraense, in the Municipality of Abaetetuba, from 2007 to 2012. The universe of research is from a school Which receives students from the outlying districts of the city and from the countryside: roads and islands. The negative reflection of the educational policy in the training reflected in the fragility of the content taught, especially for the continuity of the studies.

Keywords: educational policy; formation; student; Amazônia.

Résumé: La recherche visait à étudier les politiques éducatives de l'école secondaire dans l'État de Pará et son rôle dans la formation des étudiants dans une école publique Amazônia Paraense dans la municipalité de Abaetetuba, de 2007 à 2012. L'univers de recherche est une école l'accueil des étudiants zones périphériques de la ville et des champs, des routes et des îles. Il a été noté l'impact négatif de la politique éducative dans la formation traduit par la fragilité du contenu, en particulier pour la poursuite des études.

Mots-clés: politique éducative; la formation; étudiant; Amazônia.

Resumen: La investigación objetivó el estudio de las políticas educativas de la Enseñanza Media en el Estado de Pará y su papel en la formación de estudiantes en una escuela pública de la Amazônia Paraense, en el Municipio de Abaetetuba, en el período de 2007 a 2012. El universo de la investigación es de una escuela Que recibe alumnos de los barrios periféricos de la ciudad y provenientes del campo: carreteras e islas. Se constató el reflejo negativo de la política educativa en la formación traducida por la fragilidad de los contenidos ministrados, en especial para la continuidad de los estudios.

Palabras clave: política educativa; formación; estudiante; Amazônia.

\footnotetext{
${ }^{1}$ Universidade Federal do Pará (UFPA), Abaetetuba, Pará, Brasil.

2 Universidade do Estado do Pará (UEPA), Belém, Pará, Brasil.
} 


\section{INTRODUÇÃO}

Constituem-se como objeto de estudo deste artigo as políticas educativas do Ensino Médio no Estado do Pará e seu papel na formação de educandos, pertencentes a uma escola pública da Amazônia Paraense, no Município de Abaetetuba, abrangendo o período de 2007 a 2012, tendo em vista compreender como tais políticas refletem nas expectativas das dinâmicas educacionais locais.

Falar de Ensino Médio na Amazônia paraense significa penetrar uma realidade complexa, derivada de múltiplos fatores, entre os quais citamos a sociobiodiversidade característica da região, a extensão territorial do Estado, bem como a histórica desigualdade regional que tem imperado no Brasil e reflete substancialmente no agravamento dos resultados nos indicadores do Norte e Nordeste do País, com destaque para os indicadores educacionais do Estado do Pará. Este aparece em penúltimo do ranking nacional do Ensino Médio, com o IDEB de 2,9, segundo dados do INEP de 2013.

A expansão do Ensino Fundamental no País e no Estado Pará, que o torna quase universalizado no acesso, ainda não foi capaz de superar a desigualdade educacional elevada entre as regiões e segmentos populacionais urbanos e rurais, étnicos e de gênero. A precariedade do ensino ainda é uma realidade, a distorção série-idade, condições físicas e materiais problemáticas e a falta de políticas que garantam a permanência com sucesso são elementos que evidenciam tal realidade nos municípios da Amazônia paraense.

Isto nos leva a problematizar o papel das políticas educacionais do Ensino desenvolvidas pelo Estado Paraense na formação de alunos, tendo em vista compreender como estas refletem nas dinâmicas sociais locais do Município estudado.

Assim, cabe definir esse universo da pesquisa desenvolvida, ou seja, olhar a realidade amazônica desde um lugar que pouco se estudou, mas que expressa o ambiente das populações que nela habita. Trata-se, então, de pensar a educação desde o Município de Abaetetuba, que, embora tenha uma dinâmica urbana e receba certa influência de grandes projetos industriais, perfaz em sua constituição uma forte presença de atividades tradicionais tanto na formação cultural de sua população - ribeirinhos, quilombolas e agricultores familiares - quanto na manutenção de atividades econômicas marcadamente desenvolvidas pelo extrativismo, a pesca, o artesanato e a agricultura familiar. Uma dinâmica caracteristicamente complexa, marcada pela influência do papel do Estado e do mercado nas cidades amazônicas, na linguagem de Castro (2009), demonstra uma complexa diferença na sua formação que nos leva a compreendê-las como realidades diferentes em sua origem, tanto definidas pelas atividades socioeconômicas e culturais de suas raízes históricas, quanto das relações sociais postas em sua trajetória de formação.

Desse modo, se justifica estudar o Ensino Médio na Amazônia Paraense, mais precisamente em Abaetetuba, com o desafio de realizar uma pesquisa em uma escola pública de Ensino Médio, em que, além de nos levar a repensar os saberes e as experiências de jovens alunos, o que significa muito mais do que a busca de respostas, a possibilidade de elaborar um referencial que se configure como um caminho a ser trilhado na formação de políticas voltadas à formação média, tendo como pressuposto o diálogo entre as pessoas envolvidas no processo educativo na região.

Embora constituam estrutura formal no Estado, os municípios paraenses trazem em si dinâmicas constitutivas que representam não só valores e costumes tradicionais das populações que neles habitam, como possuem injunções locais que dão características próprias às formas de ação política e de poder dos diversos agentes sociais que os compõem. 
Essa reflexão torna-se relevante porque ela muda o enfoque de se pensar os conceitos de política educacional, formação, pois os situa em um locus de agentes que representam as instâncias institucionais dos governos - e tratam do papel que a educação e/ou escola ocupam nesse espaço.

Assim, pensar a educação e/ou as instâncias institucionais no Município é compreender que, além das políticas públicas que simbolizam os investimentos econômicos, de saber e de infraestrutura, elas determinam poder de agentes sociais que representam políticas ou a hegemonia de grupos ou frações de classes sociais locais. Ou seja, um secretário de educação, um coordenador regional de ensino, bem como um diretor, professores, alunos significam tanto representação política como indicam resoluções de demandas sociais a serem solucionadas pelo Estado.

Tal percepção torna, assim, o papel da escola nesse locus como elemento fomentador tanto de possibilidade de ascensão social, respondendo ao anseio individual por elevação de conhecimento e perspectiva profissional, como também inclui a mentalidade de incorporar em seu conteúdo de formação a dinâmica do trabalho e da cultura local.

O Município então, como esse lugar de encontro, de política e de formação de cidadania, torna-se o referencial para que seja possível compreender a especificidade da dinâmica social da Amazônia paraense. É expressão do urbano e do rural, do sujeito da cidade e do campo, de homens e mulheres que fundam sua existência e perfazem um processo de vida e política.

Na verdade, as questões que norteiam este trabalho apontam para os seguintes questionamentos: a formação se insere em uma perspectiva propedêutica e urbana, desvinculada da dinâmica social local? As experiências voltadas às escolas que recebem os alunos dessa dinâmica urbana e rural cumprem um processo formativo que reflita sua cultura e necessidades de sobrevivência? O mundo do trabalho e da cultura local seriam elementos efetivos de reflexão das atividades educacionais da educação básica, mais especificamente no Ensino Médio?

Portanto, cabendo a seguinte indagação do problema de pesquisa: Qual o papel das políticas de Ensino Médio desenvolvidas pelo Estado Paraense na formação de alunos? De outro modo, a formação dos educandos reflete as implicações das políticas educacionais do Ensino Médio desenvolvidas pelo Estado do Pará no município de Abaetetuba?

Assim, este artigo propõe desvelar qual a ideia de educação incorporada nas diretrizes e orientações das políticas educacionais propostas pelo Estado Paraense voltadas ao Ensino Médio no Município. Partimos da hipótese de que falta uma sincronia entre as políticas educacionais desenvolvidas pelo Estado Paraense no Ensino Médio, com a formação dos alunos.

\section{ASPECTOS METODOLÓGICOS}

Na busca da compreensão dessa realidade, o objetivo é analisar o papel das políticas educacionais do Ensino Médio nos saberes e experiências desenvolvidas na escola mediante ações educacionais refletidas tanto no desenvolvimento do projeto político-pedagógico quanto na compreensão dos coletivos e pessoas envolvidas: alunos concluintes do Ensino Médio.

A elaboração da pesquisa passou necessariamente pelo olhar sensível e reflexivo sobre os envolvidos. Assim, a elaboração do conhecimento requer essencialmente a ação dos sujeitos que não são simplesmente informantes, mas agentes que participam (CHIZZOTTI, 2009). Dessa maneira, além dos procedimentos de investigação no âmbito interno e externo da escola, consideramos também as orientações da Secretaria de Estado de Educação do Pará (SEDUC), ouvindo os gestores que conduziram a política educacional nesse período no Estado, bem como os representantes dessa Secretaria no Município, representada pelo gestor da Unidade Regional de Ensino. 
Além disso, no desenvolvimento da pesquisa, trabalhamos com dados secundários e primários. Assim, o levantamento bibliográfico e documental teve como objetivo garantir o arcabouço teórico que deu suporte à pesquisa. O empreendimento documental e bibliográfico está centrado mais especificamente nas discussões acerca da temática pesquisada: contexto econômico-social e políticas educacionais nos planos nacional e local. A pesquisa teve como objetivo o levantamento de informações acerca dos planos e projetos governamentais para a Educação, projetos de lei, resoluções e outros documentos oficiais que ajudaram na compreensão do objeto investigado.

De outro lado, os dados primários, centrados na coleta dos dados, foram colhidos de acordo com a dinâmica da própria condução da pesquisa. Destacam-se aqui os instrumentos mais recorrentes na tradição de pesquisa no campo educacional, tais como: entrevistas semiestruturadas, além da metodologia de grupo focal no diálogo com os estudantes. Dados quantiqualitativos levantados, buscando empreender uma investigação voltada tanto à descrição e à explicação da realidade tal como se apresenta quanto ao desvelamento dos determinantes não explícitos, mas marcantes na definição das políticas educacionais do Ensino Médio estabelecidas na realidade pesquisada.

A opção por essa escola de Ensino Médio decorreu, também, do fato de ela estar localizada em um município caracteristicamente amazônico. Os discentes que frequentam essa escola, além de serem do meio popular, são em grande quantidade provenientes do campo: filhos de agricultores familiares e de populações tradicionais, como ribeirinhos e quilombolas. Esse fato é que nos exige pensar o papel das políticas educacionais em um locus que, embora urbano, forma pessoas para um universo composto de diversidades e de práticas sociais diferentes.

Quanto à escolha das turmas, a opção por aquelas do 30 ano do Ensino Médio, com discentes de idades diferenciadas e turnos diferentes decorre do fato de ensejar a compreensão sobre o universo juvenil e adulto que adentra o espaço escolar. Quanto ao número de alunos em exercício na escola, envolvidos na pesquisa com os quais o instrumento metodológico utilizado também foi o grupo focal, com os 14 participantes - divididos em três momentos e por turnos que perfaziam os horários da escola: matutino, vespertino e noturno. O método utilizado para organização e análise dos dados foi o da análise de conteúdo, o que facilitou a interpretação das respostas dadas pelos discentes pesquisados.

\section{CONTEXTO SOCIAL E POLÍTICAS EDUCACIONAIS DO ENSINO MÉDIO NO PARÁ}

Compreender o papel das políticas educacionais do Estado Pará voltadas para o Ensino Médio na formação de discentes e na prática social de egressos significa ir à busca de uma interpretação que tenha como referência uma perspectiva de mesoabordagem do fenômeno educativo, em que, além das dinâmicas locais que se constituem em tecido de realização de tais políticas, há uma conjuntura global que se funda no papel do Estado Nacional e de suas ações como fomentador e realizador de políticas voltadas ao desenvolvimento econômico, social e político, que irão refletir decisivamente na educação na Amazônia paraense.

O período que tomamos como referência para investigar se inicia em 2007 e segue até 2012, intervalo em que se observa a confluência de mudanças introduzidas tanto no Estado Nacional como supostamente na dinâmica regional do Governo paraense. A conjuntura desse momento encontra-se envolta em um contexto socioeducacional marcado por continuidades das transformações no processo de reestruturação do capital e da globalização econômica em curso no Brasil desde a década de 90 do século imediatamente passado, que se traduz no novo 
papel da ciência e da tecnologia, bem como das modificações traduzidas pela informatização e pela microeletrônica no universo da economia e do mundo do trabalho produtivo.

Compreender, entretanto, o papel das políticas educacionais do Ensino Médio desenvolvidas pelo Estado paraense no período que nos propomos estudar, significa que, além dessa conjuntura econômica, social e educacional acima exposta, que influencia efetivamente nas políticas do Ensino no Estado do Pará, esse período estava, nos marcos da gestão do Estado Nacional, com os destinos nas mãos do presidente Lula, e não representou em essência transformação nos padrões da política econômica. Há, nas análises dos intelectuais de Economia e Ciências Políticas, um momento controverso no papel das políticas do governo em questão. Para diversos autores, permaneceria nos limites dos princípios neoliberais - Oliveira (2010), Coutinho (2008). Para outros, estaria em curso um processo de retomada de uma nova fase neodesenvolvimentista - Pochmann (2011).

Quando, porém, se vai à análise das políticas sociais do governo Lula, a agenda se altera, trazendo para o Estado um papel mais próximo das demandas sociais e um redirecionamento dos investimentos em educação.

Segundo Savana Melo (2011), mesmo que se possa afirmar que tenha havido continuidades no desenvolvimento das políticas educacionais do governo anterior, centrados, principalmente, nos ditames das agências internacionais de fomento, há, inegavelmente, segundo ele, diferenças importantes na implementação das diversas políticas educacionais. Enquanto no governo Fernando Henrique se primava por uma política impositiva, o governo Lula se estabelecia por políticas de adesão, com menor resistência às suas iniciativas.

Do mesmo modo, para o mesmo autor houve diferenças significativas no que se refere ao financiamento da Educação Básica, postas principalmente na reestruturação do Fundo de Manutenção e Desenvolvimento do Ensino Fundamental (FUNDEF), substituído pelo Fundo de Manutenção e Desenvolvimento da Educação Básica e de Valorização dos Profissionais da Educação (FUNDEB).

Assim, no caminho da elaboração da política educacional, o Governo procura estabelecer outro enfoque nos princípios e diretrizes que norteariam a sua ação. Essa perspectiva encontra-se definida no Plano de Desenvolvimento da Educação (PDE), em cujo conteúdo fica evidente a necessidade de revisão das políticas educacionais voltadas para a Educação Básica.

Segundo o texto do documento, há necessidade premente de se superar o caráter dualista da formação e o olhar sobre a educação como instrumento de política fiscal e fragmentária ${ }^{3}$ tendo como ênfase a superação de uma mentalidade gerencial e mercadológica que preponderou durante o desenvolvimento das políticas educacionais do governo anterior,

Diferentemente da visão sistêmica que pauta o PDE, predominou no Brasil, até muito recentemente, uma visão fragmentada da educação, como se níveis, etapas e modalidades não fossem momentos de um processo, cada qual com objetivo particular, integrados numa unidade geral; como se não fossem elos de uma cadeia que deveriam se reforçar mutuamente. Tal visão fragmentada partiu de princípios generalistas e fiscalistas, que tomaram os investimentos em educação como gastos, em um suposto contexto de restrição fiscal. (BRASIL, 2007, p. 7).

\footnotetext{
${ }^{3}$ Forma como os autores que analisaram a economia durante a gestão do governo do presidente Fernando Henrique Cardoso a definiram como de caráter neoliberal, centrada principalmente no ajuste financeiro e fiscal (FRIGOTTO, 1995).
} 
Quando se retomam tais reflexões direcionadas ao Ensino Médio e ao Ensino Profissionalizante, o enfoque, embora não supere por si mesmo o sentido da dualidade estrutural entre formação propedêutica e profissional, reabre a possibilidade da unidade entre o caráter geral da formação e o universo do mundo do trabalho.

No âmbito da legislação, o Decreto n. 2.208, de 17 de abril de 1997 do Ministério da Educação e do Desporto são rediscutidos e revogados com a promulgação do Decreto n. 5.154, de 23 de julho de 2004, pelo então presidente Lula. Nele se busca superar a dualidade introduzida no decreto anterior, apontando acima de tudo a integração entre conhecimento e prática, saber e domínio tecnológico e, portanto, busca a superação da dualidade entre formação propedêutica e formação profissional, dando ênfase ao Ensino Médio Integrado. Segundo Frigotto, Ciavatta e Ramos (2005), o documento é resultado da correlação de forças que se estabeleceram no âmbito interno do governo, de posições progressistas e conservadoras que se colocaram em disputa desde os embates da Constituição de 1988 e da elaboração da Lei de Diretrizes e Bases da Educação Nacional.

Essa reflexão é o substrato do entendimento da política educacional do governo Lula voltado ao Ensino Médio. Retomam-se os princípios e as diretrizes apontadas na LDB, nos artigos 35 e 36, na perspectiva de superação estrutural da dualidade histórica entre pensamento e ação, conhecimento e mundo do trabalho, buscando na mentalidade da integração firmar o tripé efetivo da ciência, da cultura e do mundo do trabalho.

Essa realidade é expressa numa certa preocupação com a reestruturação e expansão do Ensino Médio por iniciativas da esfera federal. O Governo, compreendendo a importância estratégica do Ensino Médio para a Educação brasileira, instituiu um Grupo de Trabalho (GT) Interministerial ${ }^{4}$ - Portaria n. 1.189, de 5 de dezembro de 2007, e Portaria n. 386 , de 25 de março de 2008 -, objetivando

[...] estabelecer uma política de médio e longo prazo para consolidar, no ponto de vista quantitativo e qualitativo, o ensino médio no Brasil por meio:

- de uma reestruturação do modelo pedagógico desta etapa da educação básica que colabore na superação do dualismo entre o ensino propedêutico e profissional;

- da expansão da oferta de matrículas da rede de escolas médias federais para um patamar entre $10 \%$ das matrículas totais desta etapa da educação básica.

Essas ações mais globais do governo Lula influenciariam o norte do desenvolvimento das políticas educacionais na Amazônia paraense no período de 2007 a 2012, o qual nos propomos estudar. No âmbito do discurso oficial do Governo do Estado do Pará, a linguagem é de superação de uma gestão centralizada voltada aos ditames do mercado e de parâmetros exclusivos de uma política econômica que deveria ser superada. O caminho a ser trilhado buscaria partir de uma nova dinâmica de planejamento, que incorporaria processos da gestão democrática e de participação da população na definição das demandas a serem assumidas pelo Governo do Estado nos dois biênios de sua administração.

Este enfoque encontrar-se-á nas definições das políticas públicas e nas ações do governo colocadas no PPA de 2008 a 2011, deliberadas como prioridades a serem assumidas.

Essas ações e metas foram compostas nas atividades desenvolvidas pelo Planejamento Territorial Participativo (PTP), que buscava, a partir de assembleias envolvendo os diversos setores

\footnotetext{
${ }^{4}$ Coordenado pelo Ministério da Educação e Ministério Extraordinário de Assuntos Estratégicos.
} 
sociais e as diversas regiões do Estado pensadas como território, definir demandas e prioridades nas políticas sociais a serem desenvolvidas pelo Estado paraense. Assim, então, se compunha o plano no preâmbulo norteador das estratégias de ação:

Neste contexto, o Plano Plurianual 2008-2011 foi fundamentado em um modelo inovador de planejamento e gestão, inaugurando uma nova fase no planejamento governamental com a construção e a gestão do Plano a partir de um amplo debate, buscando a implantação de um novo padrão de relação entre Estado e sociedade, marcada pela transparência, solidariedade e corresponsabilidade, consubstanciada no controle social.

A sociedade passa, então, a ser o agente de mudança para o desenvolvimento, com uma visão territorial/local de suas demandas sociais, garantido seu espaço neste novo Governo. (PARÁ, 2008, p. 02).

Esse aspecto torna-se ainda contundente quando estabelecem as ações na criação e desenvolvimento do Planejamento Territorial Participativo como instrumento de referência desse caráter democrático da gestão, buscando as diversas dinâmicas e demandas provenientes da real necessidade das populações envolvidas.

Quando se retorna aos aspectos educacionais, embora o norte da reflexão caminhe na construção fundada nesses parâmetros apontados pela gestão democrática, isto não significa dizer que, objetivamente, lograram-se avanços significativos na incorporação das demandas sociais locais. No âmbito da gestão, constitui-se de forma conturbada; durante os quatro anos de gestão, modificou-se o gestor em torno de cinco vezes, o que não simbolizava um processo permanente de continuidade das ações desenvolvida por parte de cada um deles.

Algumas ações buscaram efetivamente dar outra dinâmica ao processo educacional que se coadunava com a mentalidade descrita nas ações de planejamento e gestão do Governo. Teve início um conjunto de seminários, fóruns, reuniões, com o intuito de reformular a legislação de ensino; diversas publicações foram encaminhadas às escolas, organismos e representações da sociedade civil com a intenção de redefinir uma nova política voltada para a Educação Básica.

Do mesmo modo, construíram-se as conferências de Educação, tanto municipais, regionais e a estadual para elaboração do Plano Estadual de Educação, aprovado no final do Governo - Lei 7.441 , de julho de 2010.

No Ensino Médio, buscaria superar a dualidade sistêmica traduzida nos governos anteriores. Por via Secretaria de Estado de Educação (SEDUC) - reincorporaram-se as Escolas de Trabalho e Produção ao sistema formal de ensino, da mesma forma que se buscou, por via das diversas publicações, estabelecer novos marcos ao Ensino Médio, tendo como influência os parâmetros definidos pelo Governo federal tanto nas balizas do Decreto 5.154/2004, quanto da Resolução 04/2010, que reformula as diretrizes curriculares da Educação Básica, em que ambos redefiniriam o caráter identitário do Ensino Médio, resgatado no conceito da integração e da formação geral e mundo do trabalho.

Se, por um lado, porém, no âmbito institucional, o Governo apontou avanços nas legislações e nos procedimentos, por outro, nos parece que, por falta de uma maior organização interna e de um processo de intervenção sistêmica efetiva, aparentemente as ações acabaram por constituírem-se de maneira isolada, sem que se efetivassem como políticas públicas.

Quando se retorna ao caráter regional do sistema público de ensino, voltado aos municípios fincados nas dinâmicas amazônicas, não se vislumbrou no âmbito organizacional uma descentralização efetiva que fosse capaz de gerar nas Unidades Regionais de Ensino (URES) processos 
descentralizados que possibilitassem construções diferenciadas e experiências próprias, ou ainda que refletissem as dinâmicas das injunções sociais e da cultura local. As carências infraestruturais permanecem, a universalização ainda não se constituiu e a formação está distante de uma prática social cidadã que reflita a cidadania e o mundo do trabalho local.

A imagem que ainda se vislumbra, pois, é que, no Ensino Médio, a formação na escola se insere numa realidade de cunho propedêutico e urbano frágil, sem um vínculo efetivo com espaço social local; as realidades da formação nas escolas dos municípios que recebem os alunos dessa dinâmica rural e urbana convivem com um processo formativo distante de sua cultura e necessidades de sobrevivência; e o mundo do trabalho e da cultura local está longe das atividades educacionais propostas ao Ensino Médio.

Ante o exposto, fazem-se os seguintes questionamentos: em que medida as políticas educativas do Ensino Médio no Estado do Pará refletem na formação dos educandos no município? O que orientou a dinâmica de formação do Ensino Médio no período que nos propomos estudar, de 2007 a 2012 ?

\section{POLÍTICA EDUCACIONAL E SEU REFLEXO NA FORMAÇÃO DOS DISCENTES}

Assim, quando se vai ao universo dos participantes da pesquisa, as vozes trazem o conflito entre a dinâmica da política posta em prática pelo Governo do Estado paraense e a formação no Município estudado. O que está em pauta é a necessidade de superação da dualidade sistêmica da expansão que não conseguiu responder aos anseios de formação do conjunto populacional a ser atendido. No discurso está a imperiosa urgência de integração entre o processo formativo e o mundo do trabalho. Esta é a tônica das vozes que ressoam sobre a realidade educacional da escola pública do Município, elemento que reforça a interpretação de Marise Ramos, quando estuda o perfil da política educacional voltada à Educação Básica e à Formação Profissional, a partir dos anos 1990 do século anterior. As reformas tinham como principal objetivo as demandas levantadas pelo mercado, em detrimento de uma formação integral que respondesse às necessidades humanas, o que aprofundou o fosso entre a formação geral e o mundo do trabalho, o que, na linguagem dos gestores do sistema, influenciaria peremptoriamente na política educacional dos governos paraenses. Ainda, segundo Ramos (2012, p. 35), "A posição descolada da educação profissional e tecnológica em relação ao sistema educacional, assim como as políticas de formação para o trabalho, passou a ser orientada para os programas da capacitação de massa", o que refletiu efetivamente nas consequências formativas da escola pública no Brasil, separando formação geral de preparação para o trabalho. O mesmo refletiu na perspectiva da formação do Ensino Médio regular e/ou profissional do Estado paraense e, por conseguinte, no Município e na escola pesquisada, permanecendo o sentido da dualidade sistêmica e não respondendo ao anseio de um número considerável de alunos.

Isso demonstra o que se vem afirmando acerca da distância do conhecimento oficial com os anseios dos que adentram a escola provenientes do meio popular, o que exige das instituições públicas outra dimensão de currículo, com uma formação crítica capaz de dar a essas pessoas possibilidades de conhecimento e reconhecimento destes como sujeitos de direito.

Assim, o Ensino Médio constitui etapa obrigatória da formação, pela obrigatoriedade das requisições dos demais níveis de ensino e da premente exigência para o emprego. Há o reconhecimento da formação no Ensino Médio como etapa de conhecimento mais aprofundado do Ensino Fundamental, momento de amadurecimento pessoal e de escolhas para a vida. Os 
alunos retomam a compreensão de tempo de passagem e amadurecimento indispensável para tomada de decisão e de escolhas dos novos rumos, tanto pessoais como profissionais, ou seja, de pensar o futuro e de buscar as qualificações necessárias. Torna-se, portanto, uma referência tanto para os que buscam a continuidade dos estudos em direção à universidade, como para os que tencionam uma formação para o trabalho em nível técnico.

Então o Ensino Médio é uma etapa para que possamos concluir; é o nosso futuro, no ensino médio aprendemos muitas coisas, coisas mais avançadas então é uma etapa, o início para que possamos conseguir entrar em uma universidade nos prepara para a gente fazer o vestibular e não só isso, para o trabalho, para o emprego. (ALUNO C - Tarde).

É o nosso futuro, porque uns vão decidir se vão fazer faculdade, uns vão querer um curso técnico, outros vão querer trabalhar em outras coisas em outras funções; além do que o terceiro ano do médio vem ajudando bastante para agente possa conseguir o que almejamos. Ele é mais aprofundado. (ALUNA B - Manhã).

E conclui a aluna seguinte, destacando esse tempo de passagem e obrigatoriedade para os níveis seguintes na formação e na vida:

[..] o terceiro ano hoje para muitos não vale muita coisa. Mas o terceiro ano, o Ensino Médio é fundamental. Cada etapa da nossa vida é importante, desde lá do primeiro até a última fase de estudo, até quando tiver fazendo a faculdade, tudo é fundamental. Só que para quem se dedica, não só a uma faculdade, mas também para fazer um curso técnico ou se empregar, o ensino médio é essencial. (ALUNO A - Noite).

Esse sentido exposto nas falas anteriores recupera o caráter teórico, mais especificamente trabalhado por Arroyo (2011), quando reflete sobre o conflito ou a tensão permanente do conhecimento na escola pública. Ele não só põe em questão o papel do conhecimento oficial, da cultura escolar, mas, e principalmente, afirma que os coletivos trazem consigo novas histórias e identidades, pondo novos enfoques nas práticas formativas e, de certo modo, reabrem caminho para se discutir o papel do Ensino Médio na sociedade. Ainda conforme o autor, "Vivemos um impasse na sociedade que chega à docência, às escolas e aos currículos" (ARROYO, 2011, p. 124).

Por outro lado, surge nas vozes a tensão com a negação da qualidade do conteúdo recebido. O aspecto que é destacado é do caráter da fragilidade do conteúdo repassado no processo de formação. Embora em suas vozes haja o reconhecimento da importância do Ensino Médio, porém enfatizam que o desenvolvimento do conhecimento não está adequado à necessidade de aprofundamento. Por ser esse período intermediário, há a premente busca por melhor qualificação que não é encontrada somente na escola. Em suas expressões, para quem busca um emprego mais qualificado e a formação para a continuidade dos estudos, o conteúdo repassado não corresponde. O ensino, para a aluna entrevistada, ainda é frágil:

Particularmente, eu não posso falar assim: "Ah! Eu estou preparada para fazer uma faculdade, preparada para fazer uma prova do Enem e outras coisas". Aqui na escola não estou preparada. Fazendo a comparação do conteúdo ensinado com a de outras escolas, o que nós temos aqui não prepara para continuidade dos estudos, não aprofunda para se fazer uma prova assim, entendeu. (ALUNA C - Tarde).

A aluna seguinte dá ênfase à fragilidade do conteúdo e fala da necessidade de reforço.

Acho que uma pessoa que estuda só na escola pública, com notas, não está preparada para entrar ou fazer o nível superior. É por isso que hoje se tem cursinho para reforçar a preparação. Porque o Ensino Médio ajuda muito para gente saber, mas, em minha opinião, somente 
ele na sociedade não te dá qualificação necessária para cursar o nível superior. Pessoas que estão fazendo cursinho hoje são porque elas compreendem que só o Ensino Médio não dá essa formação. (ALUNA A - Manhã).

De tal modo, se percebe é que para os alunos entrevistados o Ensino Médio traz a contradição inerente ao seu papel definido na política educacional. É tempo de passagem, local legítimo da formação. Por outro lado, pelos percalços estruturais, sua formação torna frágil e pouco reflete na preparação, principalmente, para a continuidade dos estudos e ao mundo do trabalho, pois quem a este aspira tem que buscar complemento de formação em outros lugares, em especial em cursinhos preparatórios. Segundo os discentes, a maioria não havia se inscrito no concurso vestibular porque não se sentia preparada. Os que o fizeram estavam desde o início do ano fazendo formação paralela nos cursos preparatórios. Somado a isso vêm, ainda a falta de estrutura da escola, a carga horária excessiva dos professores e o descompromisso do Governo e/ou do Estado em relação à escola pública, o que leva à desmotivação e à evasão dos alunos; fato demonstrativo do reflexo negativo da política educacional na formação desenvolvida no universo escolar.

A continuidade desse discurso permanece quando se reflete com os alunos sobre a preparação para o trabalho, o conflito entre a resignação e a crítica no conteúdo das falas. Novamente, há a dessignificação do reflexo das proposições educacionais do sistema com as necessidades das populações atendidas. A negação da integração como elemento essencial da expansão trouxe a permanente distância entre os objetivos da política, a formação na escola e o real sentido e interesse do aluno.

Destaca-se que a formação recebida na escola não dá uma preparação assim tão qualificada, capaz de dar acesso às grandes ocupações industriais. Isto só é possível se eles, além do Ensino Médio, buscarem cursos que deem uma formação específica, tanto para o comércio local quanto para empregos na indústria. Na linguagem dos alunos, não há estrutura na escola que favoreça tal finalidade. Mesmo uma formação básica de informática é pouco pensada, ainda que a escola possua um laboratório. Isto reforça o sentido da dualidade sistêmica na expansão do Ensino Médio para as cidades do Estado paraense. Como afirma a aluna,

Então esse conhecimento que falta é que procuro em cursinho, e em escolas profissionalizantes. E eu acho que o ensino médio, terceiro ano que eu estou cursando, há muita carência dessa preparação para o mercado de trabalho. A informática que é importante não se vê na escola mesmo que exista o laboratório. (ALUNA B - Tarde).

Por dentro dessa reflexão, complementam os discentes seguintes, chamando a atenção para a carência na formação para o mundo do trabalho em especial, para empresas de maior porte, principalmente de quem está concluindo o Ensino Médio:

Assim, se você trabalhar numa loja, você tem que fazer um curso de operador de caixa, por exemplo, então é algo fora da escola, do Ensino Médio. Então foco sim essa carência, eu saindo daqui da escola no meu último ano, eu não vou a lugar nenhum ou empresa de grande porte, citando, por exemplo, Alunorte, só com o meu certificado do ensino médio conseguir um bom emprego não, então tenho que fazer um curso técnico ou fazer faculdade para poder conseguir um emprego bom. (ALUNA C - Tarde).

Essa reflexão demonstra como não houve, nos anos que enfocamos no estudo, na perspectiva da expansão do Ensino Médio para os municípios, a proposição do Ensino Médio Integrado, como forma de amenizar a dualidade sistêmica na política de Educação do Estado dos anos anteriores. Confirmando o que se refletiu, as proposições sistêmicas ficaram muito mais 
na intencionalidade do que efetivamente chegam ao universo escolar. Os aspectos enfocados na proposta curricular permaneceram no Ensino Médio Regular, na ênfase da formação para continuidade dos estudos em detrimento das demais dimensões formativas, estabelecendo, portanto, o papel ideológico e de classe ocupado pelo conhecimento oficial como define Apple (2006), determinando para diversos setores sociais o lugar de ocupação no processo de produção.

\section{ELEMENTOS CONCLUSIVOS}

Essas conclusões respaldam-se na linguagem dos alunos, quando expressam seu entendimento acerca do reflexo da formação e reafirmam o sentido do conflito entre a dinâmica da política posta em prática pelo Governo do Estado paraense e a formação no Município estudado, o que está em pauta é a necessidade de superação da dualidade sistêmica da expansão que não conseguiu responder aos anseios de formação do conjunto populacional a ser atendido. No discurso está a imperiosa urgência de integração entre o processo formativo e o mundo do trabalho. Esta é a tônica das vozes que ressoam sobre a realidade educacional da escola pública do Município. As falas discentes, no entanto, também apontam para perspectivas positivas nessa formação. Quando provocados sobre o sentido da escola em sua vida, apesar de reconhecerem a fragilidade do aprendizado, emitem valores importantes: primeiro, legitimam a escola como esse local de aprendizado, afirmam que, apesar das dificuldades se o aluno se dedicar, ele aprende. Segundo, é também o lugar da formação pessoal e do aprendizado para o convívio social, surgindo em suas falas a dimensão da ética, do aprendizado do modo de expressar e de levar para a vida conhecimentos importantes para sua prática social. Refletem o sentido de gostar da escola, local de encontro, de formação da amizade e de saber conviver em sociedade.

\section{REFERÊNCIAS}

APPLE, Michael W. Ideologia e currículo. Tradução de Venícius Figueira. 3. ed. Porto Alegre: Artes Médicas, 2006.

ARROYO, Miguel G. Currículo: território em disputa. Petrópolis, RJ: Vozes, 2011.

BRASIL. Secretaria de Assuntos Estratégicos da Presidência da República. [Gt Interministerial Instituído pela Portaria n. 1189, de 05 de dezembro de 2007, e a Portaria n. 386, de 25 de março de 2008]. Reestruturação e expansão do ensino médio do Brasil. Brasília, 2008. 28p. (Versão preliminar).

. Plano de Desenvolvimento da Educação. Brasília: MEC, 2007.

. Decreto n. 5.154, de 23 de julho de 2004. Regulamenta o $\S 2 \stackrel{\circ}{=}$ do art. 36 e os arts. 39 a 41 da Lei n. 9.394, de 20 de dezembro de 1996, que estabelece as diretrizes e bases da educação nacional, e dá outras providências. Diário Oficial [da] Republica Federativa do Brasil, Brasília, DF, 26 jul. 2004. Seção 1. p. 18.

. Decreto n. 2.208, de 17 de abril de 1997. Regulamenta o $\S 20$ do art. 36 e os arts. 39 a 42 da Lei n. 9.394, de 20 de dezembro de 1996, que estabelece as diretrizes e bases da educação nacional. Diário Oficial [da] Republica Federativa do Brasil, Brasília, DF, 18 abr. 1997. Seção 1. p. 7760.

CASTRO, Edna Maria Ramos. Urbanização, pluralidade e singularidades das cidades amazônicas. In: CASTRO, Edna Maria Ramos (Org.). Cidades da floresta. 1. ed. São Paulo: Annablume, 2009. p. 13-39. v. 1.

CHIZZOTTI, Antonio. Pesquisa em Ciências Humanas e Sociais. 10. ed. Campinas, SP: Cortez, 2009. (Biblioteca da Educação. Série 1. Escola; v. 16);

COUTINHO, Cláudio N. A Hegemonia da pequena política. In: OLIVEIRA, Francisco de; BRAGA, Ruy; RIZEK, Cibele (Org.). Hegemonia às avessas: economia, política e cultura na era da servidão financeira. São Paulo: 
Boitempo, 2010.

FRIGOTTO, Gaudêncio. Educação e a crise do capitalismo. São Paulo: Cortez, 1995.

FRIGOTTO, Gaudêncio; CIAVATTA, Maria; RAMOS, Marise. A gênese do Decreto n. 5.154/2004: um debate no contexto controverso da democracia restrita. In: FRIGOTTO, Gaudêncio; CIAVATTA, Maria; RAMOS, Marise (Org.). Ensino Médio Integrado: concepção e contradições. São Paulo: Cortez, 2005.

MELO, Savana Diniz G. Políticas para o Ensino Médio e a Educação Profissional: implicações sobre o trabalho docente na Argentina e Brasil. In: OLIVEIRA, Dalila; DUARTE, Adriana (Org.). Politicas públicas e educação: regulação e conhecimento. Belo Horizonte: Fino Traço, 2011.

OLIVEIRA, Francisco de. Hegemonia às avessas. In: OLIVEIRA, Francisco de; BRAGA, Ruy; RIZEK, Cibele (Org.). Hegemonia às avessas: economia, política e cultura na era da servidão financeira. São Paulo: Boitempo, 2010.

PARÁ (Estado). Plano Plurianual - 2008-2011. Belém, 2008.

POCHMANN, Marcio. Desenvolvimento e perspectivas novas para o Brasil. São Paulo: Cortez, 2010.

RAMOS, Marize. A educação tecnológica como política de Estado. In: OLIVEIRA, Ramon (Org.). Jovens, ensino médio e educação profissional: políticas públicas em debate. Campinas, SP: Papirus, 2012.

\section{Sobre os autores:}

Afonso Welliton de Sousa Nascimento: Graduação em Licenciatura Plena em Ciências Sociais pela Universidade da Amazônia, e em Licenciatura Plena em Pedagogia pela Universidade Federal do Pará. Mestrado em Educação pela Universidade Estadual Paulista Júlio de Mesquita Filho. Doutorado em Educação pela Universidade Federal do Ceará. Atualmente é ViceDiretor da Faculdade de Ciências Exatas e Tecnologia, Coordenador do Curso de Educação do Campo da Universidade Federal do Pará Campus Universitário de Abaetetuba. E-mail: afonsows27@gmail.com

Yvens Ely Martins Cordeiro: Graduação em Ciências Biológicas pela Universidade Federal do Pará. Mestrado em Ciências Agrárias, Área de Concentração em Biologia Vegetal Tropical, pela Universidade Federal Rural da Amazônia. Doutorado em Ciências Agrárias, Área de Concentração Agroecossistemas da Amazônia, pelo Convênio UFRA / EMBRAPA. Professor Adjunto I, da Universidade Federal do Pará, atuando principalmente na pesquisa, ensino e extensão, na área da educação no campo, especificamente com temas relacionados às práticas agroecologias na agricultura familiar. E-mail: yemcordeiro@ufpa.br

Francinei Bentes Tavares: Graduação em Licenciatura em Ciências Agrárias pela Universidade Federal do Pará (UFPA). Mestrado em Desenvolvimento Rural e Doutorado em Sociologia pela Universidade Federal do Rio Grande do Sul (UFRGS). Professor Adjunto II da UFPA- Campus Universitário de Abaetetuba. E-mail: frankbentes@gmail.com

Norma Ely Santos Beltrao: Graduação em Engenharia Civil pela Universidade Federal do Pará. Mestrado em Engenharia de Produção pela Universidade Federal de Santa Catarina. Doutorado em Economia Agrícola na Justus-Liebig-Universität Giessen na Alemanha, reconhecido pela Universidade Federal do Rio Grande do Sul (UFRGS) como Doutorado em Desenvolvimento Rural. Professora Adjunta da Universidade do Estado do Pará, atuando no Departamento de Ciências Sociais Aplicadas, e professora permanente do Programa de Pós-Graduação em Ciências Ambientais (mestrado). E-mail: normaelybeltrao@gmail.com 